\title{
Tonio: Telling Time
}

What did he already know, straddling his mother's broad lap,

hiding his face, listening at our halting and stuttering and murmuring babble, the nonsensical sounds of statistics and 'choices' rushing like noise,

perplexing his parents past their own understanding, shifting from one leg to the other, unfathomed, watching the waters well up around him, then spill,

Of the future, for the first time foreseen, far from the red-and-blue striped swingsets and the ants and the pebbles at the playground, far from the bright candy wrappers at the deli, and his mother's silken neck, where he loved to rub his hot cheek?

Tonio turned, eyes wide, cried and clung a while, his tears obscuring the flood of our own fears.

Slowly the quietness of the small room returned. He had spied the box of silly, tattered toys; he wanted them, right now, endearing just for the present, silent of their own irrelevant past.

\section{Ron Louie}

Correspondence to Dr Ron Louie, Department of Pediatrics, University of Washington School of Medicine, 4800 Sand Point Way NE, Seattle, Washington 98195-6340, US; ronlouie@blarg.net

Disclaimer This is a heavily revised new version of a poem that had been previously published in HospitalPediatrics 2015;5;43.

Competing interests None declared.

Provenance and peer review Not commissioned; internally peer reviewed.

(C) Article author(s) (or their employer(s) unless otherwise stated in the text of the article) 2017. All rights reserved. No commercial use is permitted unless otherwise expressly granted.

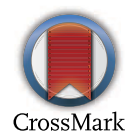

To cite Louie R. Med Humanit 2017;43:e34.

Published Online First 24 July 2017

Med Humanit 2017;43:e34. doi:10.1136/medhum-2017-011277 